\title{
Evaluation of Container Ship Maneuvering Characteristics from View Point of Ship Handling Ability
}

\author{
PHAM Van Thuan ${ }^{*}$ and KOBAYASHI Hiroaki ${ }^{* *}$
}

\begin{abstract}
If the ship handling ability can be evaluated, the safety of navigation would be assured. Generally, the handling ability has not been defined yet. In this paper, the handling ability is called as the handlability.

In order to define the ship handlability, we have been developing a standard evaluation method by the basic of difficult situation. The difficult situation is the approaching jetty. The handlability includes both of ship maneuverability and human characteristics. Numerical simulations are carried out to estimate the ship maneuverability. By comparing between numerical simulations results and mariner handling results, we evaluate the ship maneuvering characteristics under control of human. These evaluations enable us to define standard criteria on the handlability. In this paper, the study of a container vessel is introduced.
\end{abstract}

Keywords: Handlability, Human factor, Ship maneuvering, Stopping, Altering course

\section{Introduction}

Handlability of a ship is the ability to handle the ship to complete the task of bringing the ship from port to port safely. When the handlability is defined, the safety of navigation is evaluated. However, the handlability has not been defined yet. In chapter 2 , the components of the handlability are pointed out and the method for defining handlability in the approaching jetty situation is proposed.

The ship maneuverability shows the ability of the ship to environment without the influence of human. It is one component of handlability. In chapter 3, the way to estimate the ship maneuverability by numerical simulation is shown.

The characteristics of human in controlling the ship show the relations between the handlability and maneuverability of the ship. In chapter 4 , these relations are defined.

\section{Handlability of the ship}

Without control of human, ship has her maneuverability. Under the control of human, known as human characteristics, the handlability is shown. Handlability of the ship is the combination of ship maneuverability and human characteristics.

The ship maneuverability can be estimated by numerical simulation.

The human characteristics cause the differences between actual handling results and ship maneuverability. Therefore, experiments should be carried out to get actual handling results. Then, we compare actual handling results with ship maneuverability to get human characteristics.

We estimate handlability from ship maneuverability and human characteristics.

In the situation of approaching jetty, the ship must follow plan strictly. Mariners have to use all of their control ability and ship maneuverability to handle the ship. Then, the handling ability is shown clearly. So, the study of handlability can be carried out in this situation.

A navigational plan can be divided into each specific part for estimation of handlability.

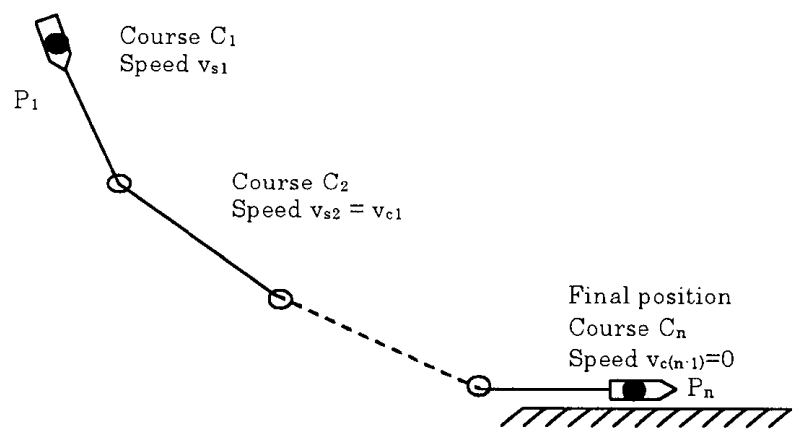

Fig. 1 Navigational plan

Figure 1 shows one normal navigational plan of approaching jetty. When approaching the jetty, the ship navigates in 3 kinds of motions: straight running (figure 2), altering course (figure 3 ) and stopping the vessel (figure 4). For estimating the handlability of the ship, these 3 kinds of motions should be studied.

In figure $2,3,4$, the items are explained as following:

$\mathrm{v}_{\mathrm{s}}$ : speed when straight motion is started.

$\mathrm{v}_{\mathrm{c}}$ : speed when straight motion is completed.

Dev: deviation in straight motion.

$\Delta \mathrm{d}$ : running distance in straight motion.

$\mathrm{v}_{\mathrm{sa}}$ : speed when altering course is started.

$\mathrm{v}_{\mathrm{ca}}$ : speed when altering course is completed.

$\operatorname{Dev}_{\mathrm{a}}$ : deviation in altering course.

$\Delta \psi$ : altering angle.

$\mathrm{d}_{\mathrm{sa}}$ : distance from the point, where mariners start altering action, to waypoint is called necessary

\footnotetext{
* Student member: Tokyo University of Marine Science and Technology (2-1-6, Etchujima, Koto ku, Tokyo 135-8533).

** Member: Tokyo University of Marine Science and Technology (2-1-6, Etchujima, Koto ku, Tokyo 135-8533).
} 
distance to start altering course.

$\mathrm{d}_{\mathrm{ca}}$ : distance from waypoint to the point, where mariners complete bringing the ship to new course line, is called necessary distance to complete altering course.

$\mathrm{v}_{\mathrm{st}}$ : speed at point mariners start reducing speed by using astern revolution is called stopping speed.

$\mathrm{d}_{\mathrm{s}}$ : distance from the position where mariners start using astern revolution to final position is called stopping distance.

$\operatorname{Dev}_{\mathrm{st}}$ : deviation in stopping motion.

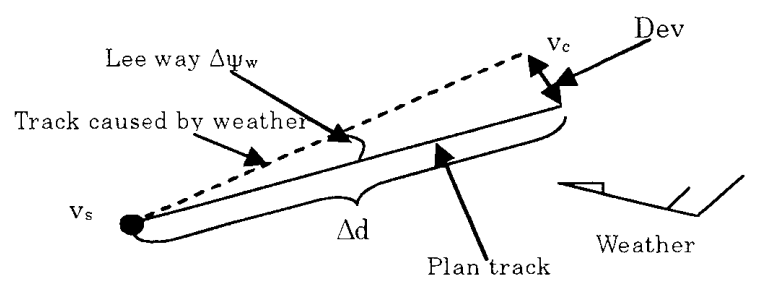

Fig. 2 Straight running motion

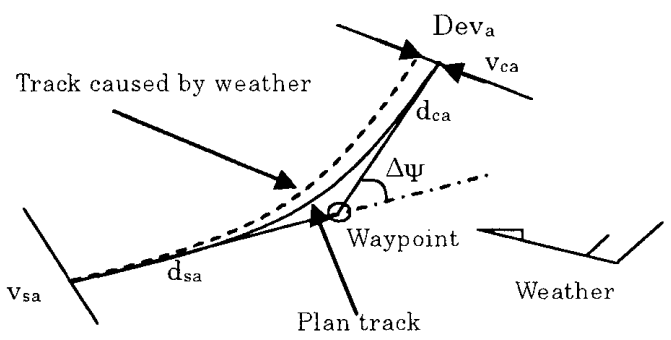

Fig. 3 Altering course motion

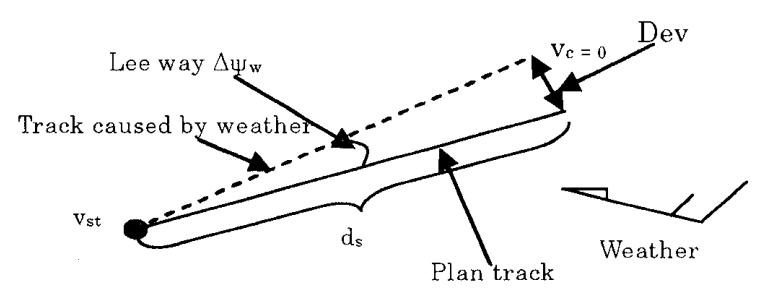

Fig. 4 Stopping motion

One navigational plan may consist of 2 or 3 kinds of running motions. Handlability in one navigational plan is the combination of handlability in each motion.

\section{Numerical simulation}

Numerical simulations are carried out with the mathematical models of the ship for above 3 kinds of running motions. The results of numerical simulations show the ship maneuverability.

Ship maneuverability is indicated by the relations of the factors in each running motion. In straight running motion, that is the relation between $v_{s}$ and $\left(\Delta d, v_{c}\right)$. In altering course, that is the relation between $\left(\Delta \psi, v_{\mathrm{sa}}\right)$ and $\left(\mathrm{d}_{\mathrm{sa}}, \mathrm{d}_{\mathrm{ca}}, \mathrm{v}_{\mathrm{ca}}\right)$. In stopping motion, that is the relation between $v_{s t}$ and $d_{s}$.

The ship maneuverability is used to compare with actual handling results to get human characteristics.

\subsection{Initial conditions of numerical simulation}

In this paper, the handlability is estimated from final stopping position to one point of navigational plan. For estimation of handling ability, firstly, the final stage of handling to berth is examined. At present time, the effect of weather conditions such as wind or current is not taken into consideration.

The model of container ship with $\mathrm{L}_{\mathrm{pp}}=196 \mathrm{~m}, \mathrm{~B}$ $=32.2 \mathrm{~m}, \mathrm{~d}=11.5 \mathrm{~m}$ was applied for the purpose of the study.

We have used this container ship for training many mariners in our ship handling simulator. We found that mariners often stop the engine from 1 nautical mile (NM) before the final position. Usually, ship proceeds to this $1 \mathrm{NM}$ point by dead slow ahead engine. We apply handling stage from $1 \mathrm{NM}$ to final position as final handling stage for our study. So, for numerical simulations, we use the conditions of initial ship's speed within the range of speed at dead slow ahead engine. Except the case of stopping motion, the numerical simulations are carried out with engine stop.

The speed at dead slow ahead engine of this container is $8.3 \mathrm{kts}$. Ship stop engine and approach jetty. Therefore, the numerical simulations are carried out with the engine conditions stop in straight running and altering course motion. In stopping motion, engine is set at every astern condition from full astern to dead slow astern. Initial ship's speed is set from $8 \mathrm{kts}$ to $1 \mathrm{kts}$ for 3 running motions.

Sometimes, the engine may be stopped when the ship speed is higher than ship's speed at dead slow ahead engine. Therefore, numerical simulations are also carried out with initial speeds: $12 \mathrm{kts}, 11 \mathrm{kts}$, $10 \mathrm{kts}$ and $9 \mathrm{kts}$.

\subsection{Control of rudder in numerical simulation}

In order to control the ship, the rudder is used. The conditions of rudder are shown as following:

- Straight running motion: rudder of the ship is kept at neutral position.

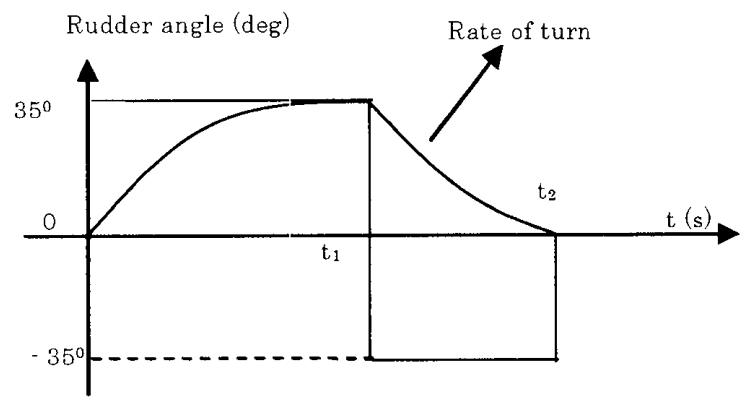

Fig. 5 Control off rudder in altering course

- Altering course motion: the BangBang control theory is applied to control the rudder of the ship in numerical simulation (figure 5). The time to steer 
the first rudder angle $\pm 35^{0}\left(t_{1}\right)$ is adjusted. After $t_{1}$, the counter rudder angle is steered. The altering course action is completed when rate of turn is zero. The altering angle is changed by adjusting $t_{1}$.

- Stopping motion: rudder of the ship is kept at neutral position.

\subsection{Comparison between numerical simulation}

\section{results of K-T model and MMG model}

Ship motions are simulated by $\mathrm{MMG}$ model and $\mathrm{K}-\mathrm{T}$ model. It is known that MMG model describes ship behaviors more precisely than $\mathrm{K}-\mathrm{T}$ model. In order to get one MMG model of the ship, it takes a lot of time and work in towing tank with model of the ship. But, the K-T model can be analyzed from zigzag test and some maneuvering tests of the vessel. If we can use results of K-T model, we can assess the handlability of many ships. Therefore, the comparison between simulation results of MMG model and $\mathrm{K}-\mathrm{T}$ model is made to access the validity of $\mathrm{K}-\mathrm{T}$ model simulation results for estimating the handlability of the ship.

The K-T mathematic model is shown as following formulae:

- Control turning: $T \cdot \ddot{\psi}+\dot{\psi}=K . \delta_{r}$

- Control speed:

$$
\dot{v}+a_{v v} \cdot v^{2}+a_{r r} \cdot r^{2}=a_{n n} \cdot n^{2}+a_{n v} \cdot n \cdot v
$$

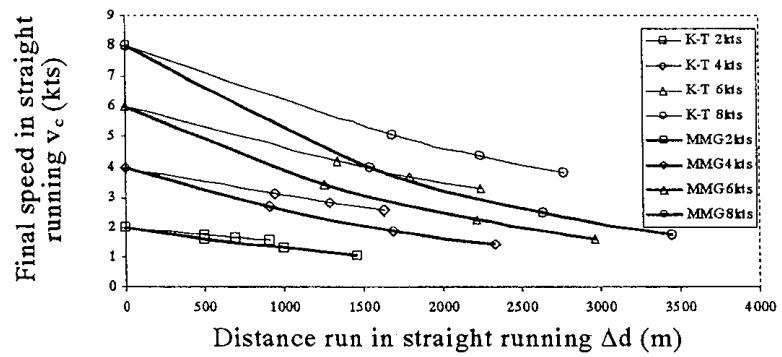

Fig. 6 Speed deduction in straight running

\section{Straight running motion}

The results of numerical simulations by MMG model and $\mathrm{K}-\mathrm{T}$ model for straight running are shown in figure 6 . Horizontal axis indicates the running distance $\Delta \mathrm{d}$, vertical axis indicates the speed after running such distance $\mathrm{v}_{\mathrm{c}}$. The bold lines indicate the results by MMG model with initial speed $8 \mathrm{kts}, 6 \mathrm{kts}, 4 \mathrm{kts}$ and $2 \mathrm{kts}$. The thin lines indicate the results by $\mathrm{K}-\mathrm{T}$ model with initial speed $8 \mathrm{kts}, 6 \mathrm{kts}, 4 \mathrm{kts}$ and $2 \mathrm{kts}$. It is found that numerical simulation results by MMG model show nearly same tendency with the results by K-T model. However, the deduction of speed by MMG is faster than the results by K-T model.

\section{Altering course motion}

The results of numerical simulations by MMG model and K-T model for altering course are shown in figure 7,8 and 9. Horizontal axes indicate altering angle $\Delta \psi$, vertical axes indicate necessary distance to start altering course $d_{\text {sa }}$ (figure 7), necessary distance to complete altering course $d_{c a}$ (figure 8), speed when altering course is completed $\mathrm{v}_{\mathrm{ca}}$ (figure 9) corresponding to altering angle $\Delta \psi$. The bold lines indicate the results by MMG model with initial speed $8 \mathrm{kts}$, $6 \mathrm{kts}$, $4 \mathrm{kts}$ and $2 \mathrm{kts}$. The thin lines indicate the results by $\mathrm{K}-\mathrm{T}$ model with initial speed $8 \mathrm{kts}, 6 \mathrm{kts}, 4 \mathrm{kts}$ and $2 \mathrm{kts}$.

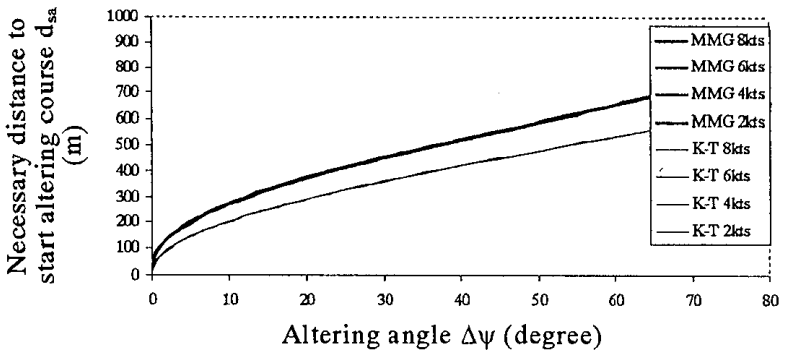

Fig. 7 Necessary distance to start altering course

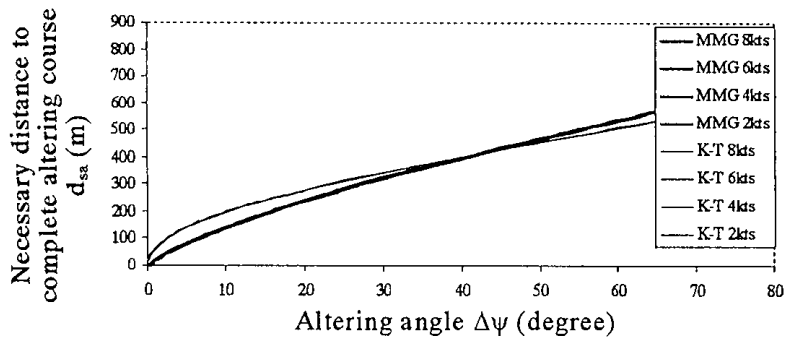

Fig. 8 Necessary distance to complete altering course

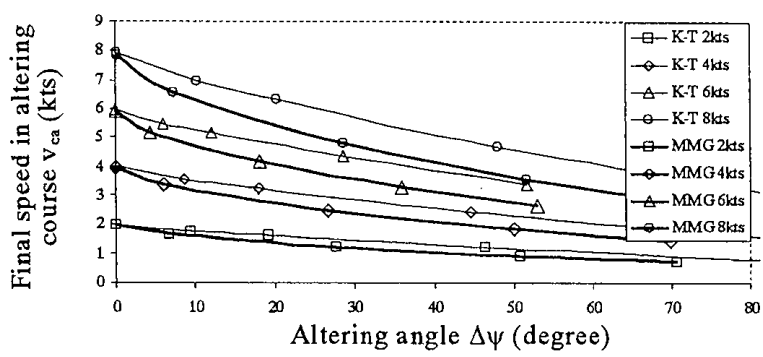

Fig. 9 Final speed in altering course

It was confirmed that the results by MMG model and the results by $\mathrm{K}-\mathrm{T}$ model have same tendency. The speed deduction by MMG model is faster than the one by K-T model. The necessary distance to start altering course and necessary distance to complete altering course are not depended on ship speed, it is depended on altering angle.

\section{Stopping motion}

The results of numerical simulations by MMG model and $\mathrm{K}-\mathrm{T}$ model for stopping motion are shown in figure 10. Horizontal axis indicates speed at point mariners start reducing speed by using astern revolution $\mathrm{v}_{\mathrm{st}}$, vertical axis indicates distance to final position when mariners start using astern revolution or stopping distance $d_{s}$ corresponding to different $v_{s t}$. Each bold line indicates the results by 
MMG model with each condition of engine. Each thin line indicates the results by $\mathrm{K}-\mathrm{T}$ model with each condition of engine.

It is recognized that $\mathrm{K}-\mathrm{T}$ model requires longer distance to stop the vessel.

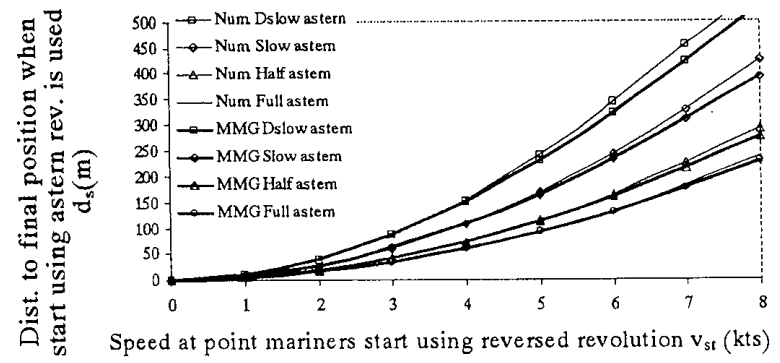

Fig. 10 Stopping distance

By comparing the simulation results between MMG model and $\mathrm{K}-\mathrm{T}$ model showing in figure 6, 7, 8,9 and 10 , it is concluded that the speed deduction when using K-T model is slower than speed deduction when using MMG model. This makes the vessel run longer distance in order to reduce same value of ship speed. It means that the maneuverability estimated from $\mathrm{K}-\mathrm{T}$ model shows lower ability than the one from MMG model. It is clear that the lower estimation value is used, the safer condition is achieved.

Comparing with MMG model, getting a K-T model is easier. The tendency of simulation results by K-T model is same. And the ship maneuverability estimated by K-T model shows safer condition. From above reasons, we can use K-T model for estimation of ship maneuverability in this study. When human characteristics in handling the ships are defined, we can combine with ship maneuverability estimated by $\mathrm{K}-\mathrm{T}$ models to get the handlability of the other ships.

\section{Experiments in ship handling simulators}

The experiments are carried out in ship handling simulator to get the actual handling results.

We get human characteristics in handling the ship by comparing the actual handling results and numerical simulation results.

After finding the human characteristics, we can estimate the handlability from ship maneuverability and human characteristics.

\subsection{Condition of experiments}

In the condition of without weather effect, it is supposed that mariners do not take any action when ship runs straightforward. So, experiments for the straight running motion are considered as same as numerical simulation results. And straight running motion is not examined in ship handling simulator.

In other cases, the conditions of experiments are set to make mariners not to take immediate action right after scenarios start. This gives mariners time to evaluate the situation and give decision as same as in real situations. The speeds of the vessel at initial point and the altering angles are set in the range of initial speed and altering angle used for numerical simulation.

Based on the above discussion, the experiments are started in the following conditions:

- Stopping motion: speeds are $8 \mathrm{kts}$ and $6 \mathrm{kts}$, when distance to final position is $1500 \mathrm{~m}$. Speed is $4 \mathrm{kts}$, when distance to final stopping position is $1000 \mathrm{~m}$.

- Altering course motion: we select 3 groups of experiments: the distance to waypoint are $1 \mathrm{NM}$ when altering angle is $60^{\circ}, 1500 \mathrm{~m}$ when altering angle is $40^{\circ}$ and $1000 \mathrm{~m}$ when altering angle is $20^{\circ}$. In each group, experiments are started with speeds at $4 \mathrm{kts}, 6 \mathrm{kts}$ and $8 \mathrm{kts}$ respectively.

- Experiments are also started with closer distance to waypoint and/or higher speed. In altering course, the distance to waypoint is $600 \mathrm{~m}$, speed is 6kts when altering angle is $40^{\circ}$. In stopping motion, speed is $10 \mathrm{kts}$ when distance to final stopping position is $1500 \mathrm{~m}$. These additional conditions are used for getting additional data to confirm the tendency of experimental data.

The ship is handled by captain or pilot in the approaching jetty situation. So, for measuring the handlability of the ship, the ship was handled by experienced captains in experiments of running motions.

For confirmation of ship position in experiments, we arranged the leading marks on the course lines. We supplied both of visual data and radar data of leading marks. In stopping motion, we arranged 1 leading light abeam of ship at designated stopping position to confirm stopping position correctly. We also set buoys at altering point and designated stopping position on radar screen only. These buoys were used to measure the remaining distance to final stopping position or to waypoint by radar.

During experiments, mariners were supported by 3 persons for steering the rudder, controlling the engine telegraph and observing the radar to check the remaining distance to final stopping position or altering point or deviations.

\subsection{Method of measuring data}

\section{Stopping motion:}

When mariners start the first action to use astern engine, the values of ship's speed $v_{s t}$ and the distance to final position $\mathrm{d}_{\mathrm{s}}$ are recorded.

\section{Altering course motion:}

When mariners start the first action to alter the course, the distance from ship's position to waypoint $\mathrm{d}_{\mathrm{sa}}$ and ship's speed $\mathrm{v}_{\mathrm{sa}}$ are recorded

When mariners cornplete altering the course, the distance from ship's position to waypoint $d_{c a}$ and ship's speed $v_{c a}$ are recorded

The altering angle $\Delta \psi$ is also recorded. 


\subsection{Comparison between experimental results and} numerical simulation results

Stopping motion:

For carrying out measuring of ability of stopping the vessel, the mariners are requested stop vessel at designated point without using ahead engine. They can use only astern engine to stop the vessel.

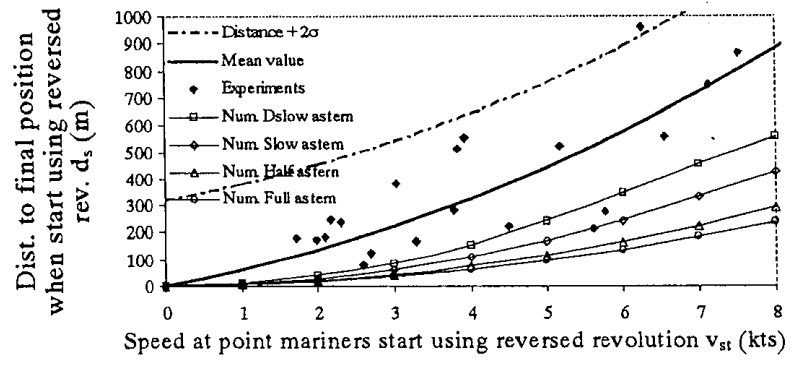

Fig. 11 Stopping distance

In figure 11, the thin lines show numerical simulation results corresponding to each astern engine telegraph position. The bold line indicates the mean value of experimental data. It shows the handlability of the ship.

The experimental data shows the same tendency as numerical simulation. The differences between numerical simulation results and experimental results are caused by human characteristics. In this case, the standard deviation $(\sigma)$ is $158 \mathrm{~m}$. According to distribution of standard deviation, if we estimate with $2 \sigma$ shown by dotted line in figure $11,95 \%$ of mariners can achieve the task of stopping the vessel in such distances. If we use the dotted line for estimation of stopping ability, the safer condition is achieved. But, in this paper, I use mean value for estimation in case study.

From the figure 11, it was confirmed that the actual stopping distances $d_{s}$ are almost twice of stopping distance estimated by numerical simulation with slow astern engine $d_{s N U}$. The relation is shown in formula (3):

$$
d_{s}=2 \times d_{s N U}
$$

\section{Altering course motion:}

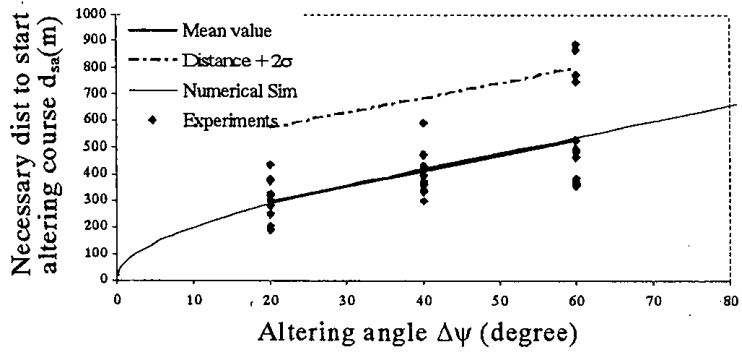

Fig. 12 Necessary distance to start altering course

The mariners are requested to handle the ship to change her course to a new course line. In case of approaching jetty, ship speed should be kept at low speed. So, for measuring handling ability, in these experiments, mariners are requested to keep ship's speed as low as possible and they can use only rudder and ahead engine for accelerating turning in altering course.

Figure 12 shows the relation of experimental data for necessary distance to start altering course $d_{s a}$ and altering angle.

The mean value of experimental data shows nearly same as numerical simulation. It means mariners need the same distance to start altering course as numerical simulation results. In this case, the standard deviation $(\sigma)$ is $137 \mathrm{~m}$. The estimation values of $2 \sigma$ are shown as dotted line in figure 12 .

The relation between actual necessary distance to start altering course $d_{\text {sa }}$ and the value estimated by numerical simulation $d_{\mathrm{saNU}}$ is shown in formula (4).

$\mathrm{d}_{\mathrm{sa}}=1 \mathrm{xd}_{\mathrm{saNU}}$

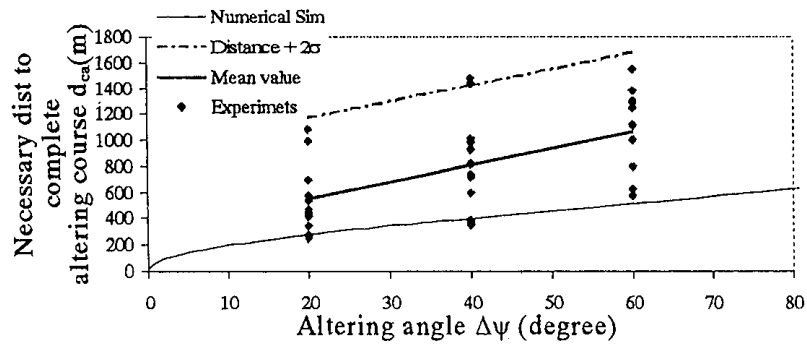

Fig. 13 Necessary distance to complete altering course

BangBang control is one of optimal controls. In figure 13, the experimental results of necessary distance to complete altering course $d_{c a}$ show that mariners can not achieve optimal control, they need longer distance to bring the ship to the new course line. The mean value of necessary distance to complete altering course is almost twice of numerical simulation results. In this case, the standard deviation $(\sigma)$ is $304 \mathrm{~m}$. The estimation values of $2 \sigma$ are shown as dotted line in figure 13.

The relation between actual necessary distance to complete altering course $d_{c a}$ and the value estimated by numerical simulation $d_{c a N U}$ is shown in formula (5).

$\mathrm{d}_{\mathrm{ca}}=2 \times \mathrm{d}_{\mathrm{caNU}}$

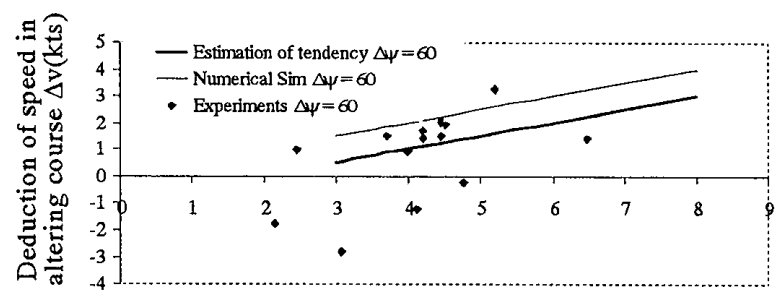

Ship's speed at point of start altering course $\mathrm{v}_{\mathrm{sa}}(\mathrm{kts})$

Fig. 14 Speed deduction in altering course $60^{\circ}$

In figure 14, vertical axis indicates the deduction of ship's speed in altering course $\left(\Delta v=v_{s a}-v_{c a}\right)$, horizontal axis indicates the speed when altering course is started $\mathrm{v}_{\mathrm{sa}}$. The thin line indicates the tendency of speed deduction in numerical 
simulation. The bold line indicates the tendency of experimental data.

The speed deduction in altering course is related to the speed when altering course is started $\mathrm{v}_{\mathrm{sa}}$ and altering angle $\Delta \psi$. The results of experiments show that the speed deduction is smaller than numerical simulation. When $\mathrm{v}_{\mathrm{sa}}$ is small, it may be changed to negative. The reason is that mariners use ahead engine revolution to assist turning. The actual deduction of speed is almost lower than numerical simulation results $1 \mathrm{kts}$. However, the distribution of experimental data is not concentrated. It may be caused by lacking of experiments. We will carry out more experiments to examine. And in this paper, I use the above relation for case study.

The relation between actual speed deduction in altering course $\Delta v$ and the value estimated by numerical simulation $\Delta \mathrm{v}_{\mathrm{NU}}$ is shown in formula (6)

$$
\Delta \mathrm{v}=\Delta \mathrm{v}_{\mathrm{NU}}-1
$$

\section{Application of study results in case of approaching Tokyo container terminal}

The numerical simulations have been carried out to estimate maneuverability of the ship. And the relations between actual handling results and ship maneuverability have been found. Based on these data, the handlability of the ship can be estimated.

When the handlability of the ship corresponding to one navigational plan can be estimated, the safety of handling for that navigational plan can be evaluated from view point of ship handlability.

In this paper, the estimation of handlability for approaching Tokyo container terminal is shown.

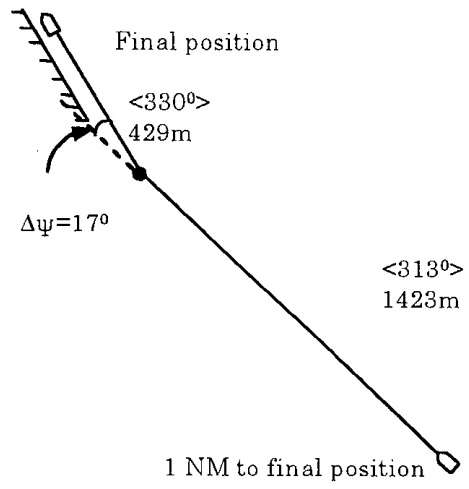

Fig. 15 Approaching Tokyo container terminal

One navigational plan for entering Tokyo container terminal is shown in the figure 15: from distance $1 \mathrm{NM}$ to final berthing position, ship navigates in the course $313^{\circ}$ in distance $1423 \mathrm{~m}$, changes her course to $330^{\circ}$ and runs $429 \mathrm{~m}$ then stops at final position.

The navigation condition: no disturbance.

We try to discuss the validity of the navigational plan based on the ship handlability. The estimation of handlability is carried out as following:

In this navigational plan, there is 1 altering point.
It is supposed that ship runs in 3 motions: straight running motion from $1 \mathrm{NM}$ point, altering course and stopping motion.

In case of altering angle $\Delta \psi=17^{\circ}$, using figure 12 , by inputting the altering angle, the numerical simulation results for necessary distance to start altering course is found: $d_{\text {saNU }}=264 \mathrm{~m}$.

The relation between actual necessary distance to start altering course $d_{\text {sa }}$ and numerical simulation value $d_{\text {sanU }}$ is shown in formula (4). The value of $\mathrm{d}_{\mathrm{sa}}$ is found: $\mathrm{d}_{\mathrm{sa}}=\mathrm{d}_{\mathrm{saNu}}=264 \mathrm{~m}$.

By inputting altering angle $\Delta \psi=17^{0}$ to figure 13 , the numerical simulation results for necessary distance to complete altering course is found: $d_{\text {caNU }}$ $=254 \mathrm{~m}$.

From formula (5), the actual necessary distance to complete altering course is found.

$\mathrm{d}_{\mathrm{ca}}=2 \times \mathrm{x} \mathrm{daNU}_{\mathrm{caN}}=2 \times 254=508 \mathrm{~m}$.

Comparing with available distance $1423 \mathrm{~m}$ before altering course and $429 \mathrm{~m}$ after altering course, it is clear that there is not enough distance to complete altering course.

It is concluded that, this navigational plan is not satisfied with the safety of handling from view point of ship handlability. It is necessary to revise this navigational plan.

After the calculation with different navigational plans with various altering angles and remain distances to stop the vessel, considering the allowance of navigational area of Tokyo container terminal, a new navigational plan is proposed as shown in figure 16.

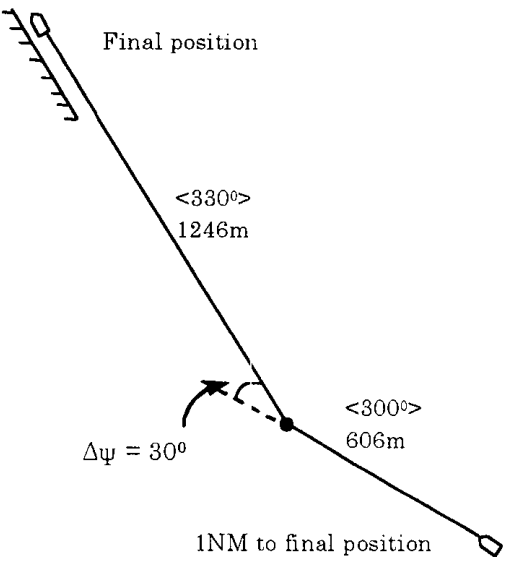

Fig. 16 Revised plan for Tokyo container terminal

By carrying out same procedure as above, the handlability is estimated as following:

In case of altering angle $\Delta \psi=30^{\circ}$, using figure 12 and figure 13 , the values of $d_{\mathrm{sa}}$ and $\mathrm{d}_{\mathrm{ca}}$ are found: $\mathrm{d}_{\mathrm{sa}}=\mathrm{d}_{\mathrm{caNU}}=357 \mathrm{~m}, \mathrm{~d}_{\mathrm{ca}}=2 \times \mathrm{d}_{\mathrm{saNU}}=2 \times 340=$ $680 \mathrm{~m}$. Comparing with available distance $606 \mathrm{~m}$ before altering course and $1246 \mathrm{~m}$ after altering course, it is confirmed that there is enough distance to complete altering course.

Action for altering course requires $d_{s a}=264 \mathrm{~m}$ and $\mathrm{d}_{\mathrm{ca}}=680 \mathrm{~m}$. So, the remaining distances in 
navigational plan are calculated as following:

Distance for straight running: $\Delta \mathrm{d}=606-264=$ $249 \mathrm{~m}$.

Distance for Stopping: $d_{s}=1246-680=566 \mathrm{~m}$.

Navigational plan is explained as: from distance $1 \mathrm{NM}$, mariner handles the ship running $249 \mathrm{~m}$ in straight running motion, altering course and stopping the vessel from distance $566 \mathrm{~m}$.

It is necessary to estimate the possibility of ship's speed at 1NM position. Base on this navigational plan, firstly, ship's speed, when mariners start stopping motion, $v_{s}$ is estimated. This $v_{s}$ is the speed when altering course being completed $\mathrm{v}_{\mathrm{ca}}$. By applying $\mathrm{v}_{\mathrm{ca}}$, the speed when altering course being started $\mathrm{v}_{\mathrm{sa}}$ is estimated. This $\mathrm{v}_{\mathrm{sa}}$ is the speed when complete straight running motion $\mathrm{v}_{\mathrm{c}}$. By applying $\mathrm{v}_{\mathrm{c}}$, the speed when of start straight running motion $\mathrm{v}_{\mathrm{s}}$ at point $1 \mathrm{NM}$ to final stopping position is estimated.

The estimation of speed is shown as following:

From formula (3), the relation of stopping distance $d_{s N U}=d_{s} / 2=566 / 2=283 m$.

With $d_{\mathrm{sNU}}$, using figure 11 with slow astern engine curve, the maximum speed at the point, where stopping action is carried out, is $\mathrm{v}_{\mathrm{st}}=6.5 \mathrm{kts}$.

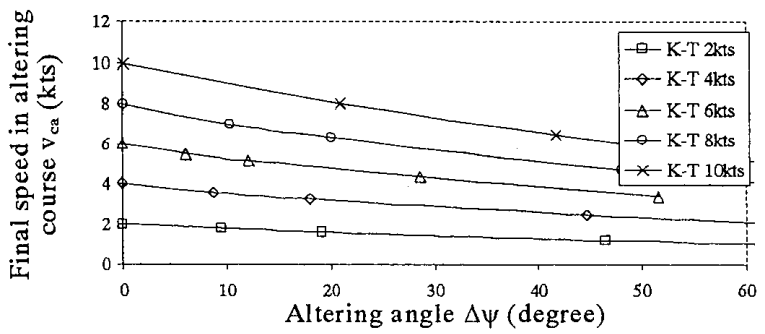

Fig. 17 Speed deduction in altering course

From $v_{\mathrm{ca}}=\mathrm{v}_{\mathrm{st}}=6.5 \mathrm{kts}$ and $\Delta \psi=30^{\circ}$, using figure 17 , we found the maximum speed before altering course $\mathrm{v}_{\mathrm{saNU}}=9.1 \mathrm{kts}$, speed deduction in numerical simulation: $\Delta v_{\mathrm{NU}}=9.1-6.5=2.6 \mathrm{kts}$. From formula (6): $\Delta \mathrm{v}=\Delta \mathrm{v}_{\mathrm{NU}}-1=1.6 \mathrm{kts}, \mathrm{v}_{\mathrm{sa}}=6.5+1.6$ $=8.1 \mathrm{kts}, \mathrm{v}_{\mathrm{c}}=\mathrm{v}_{\mathrm{sa}}$.

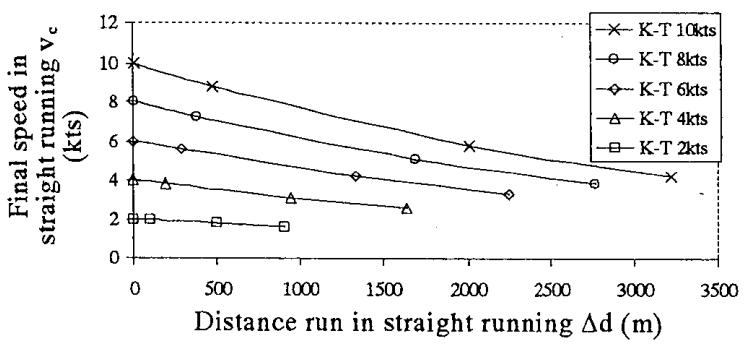

Fig. 18 Speed deduction in straight running

From $\Delta d$ and $v_{c}$, using figure 18 , we found the maximum speed at distance $1 \mathrm{NM} \mathrm{v}_{\mathrm{s}}=8.6 \mathrm{kts}$.

The result of estimation at distance $1 \mathrm{NM}$ shows as same as ship speed at dead slow ahead. It is same as supposed condition in which mariners can stop the engine from distance $1 \mathrm{NM}$ to final position and handle to final point safely.

Based on the discussions, a new navigational plan is proposed. The altering point is $1246 \mathrm{~m}$ to final position and altering angle is changed to $30^{\circ}$. With this navigational plan, mariners can handle the ship to the final position safely.

By using our method, which is mentioned in this paper, for estimation of handlability, mariners can make rational plan of navigation.

\section{Conclusions}

In this paper, the necessary items for estimating handlability were pointed out.

The comparison between numerical simulation results of MMG model and $\mathrm{K}-\mathrm{T}$ model has been made. From the view point of safety navigation, numerical simulation results of $\mathrm{K}-\mathrm{T}$ model can be used for estimating handlability of ship. It is very useful and convenient in marine practice.

The actual handling results of container ship are compared with numerical simulation results. The numerical simulation results show the estimation of ship maneuverability. The relations between actual handling results and ship maneuverability (human characteristics) are shown. These relations are used to estimate handlability of the ship in real situation of approaching harbor.

The method of estimating handlability of the ship from ship maneuverability was proposed. Based on the ship maneuverability estimated by numerical simulation and relation between ship maneuverability and actual handling results, the ship handlability is estimated.

When the handlability is estimated, the safety of navigation can be evaluated. The results of this concept can be used to make navigational plan and used as reference for design channel.

\section{Questions and Answers:}

\section{SERA Wataru (Kobe University)}

When mariner change the ship's course, it is necessary to consider the effect of rudder. How do you decide the condition of rudder angle?

\section{PHAM Van Thuan}

Thank you very much for your question. I fully agree that the effect of rudder is related to changing course action. However, in actual handling situations, mariners use various kinds of rudder angle when altering course. It is difficult to define handlability based on condition of rudder angle. So, we do not use conditions of rudder for study the handlability of the ship. We use other parameters for study altering course motion: Necessary distance to start altering course, Necessary distance to complete altering course and speed deduction in altering course. 